\title{
Llibre Blanc de l'Eurodistricte Català Transfronterer: creació de projecte i reestructuració territorial
}

\section{Margarida Castañer \\ Jaume Feliu \\ Obdúlia Gutiérrez}

Universitat de Girona. Departament de Geografia

mita.castaner@udg.edu

jaume.feliu@udg.edu

obdulia.gutierrez@udg.edu
Recepció: setembre 2010

Acceptació: desembre 2010

\section{Resum}

En aquest article, s'hi presenta el procés d'elaboració, la metodologia, les reflexions i les conclusions del Llibre Blanc de l'Eurodistricte Català Transfronterer elaborat per la Mission Opérationnelle Transfrontalière (MOT) i la Universitat de Girona (UdG). L'estudi té per objectiu acompanyar la definició i l'emergència d'un projecte de territori transfronterer basat en la realitat d'un àmbit territorial compartit entre el departament dels Pirineus Orientals i les comarques de la província de Girona. El contingut del Llibre Blanc es divideix en tres parts: un diagnòstic transfronterer complet, l'anàlisi dels reptes d'aquest territori i les opcions de governança del territori transfronterer. Després de descriure el context territorial, la metodologia i les conclusions de l'estudi, s'hi fa un breu repàs de quin és l'estat del procés en l'actualitat.

Paraules clau: espai català transfronterer; Eurodistricte; governança.

Resumen. Libro Blanco del Eurodistrito Catalán Transfronterizo: creación del proyecto y reestructuración territorial

Se presenta el proceso de elaboración, la metodología, reflexiones y conclusiones del Libro Blanco del Eurodistrito Catalán Transfronterizo elaborado por la Mission Opérationnelle Transfrontalière (MOT) y la Universidad de Girona (UdG). El estudio tiene por objetivo acompañar la definición y la emergencia de un proyecto de territorio transfronterizo basado en la realidad de un ámbito territorial compartido entre el departamento de los Pirineos Orientales y las comarcas de la provincia de Gerona. El contenido del Libro Blanco se divide en tres partes: un diagnóstico transfronterizo completo, el análisis de los retos de este territorio y las opciones de gobernanza del territorio transfronterizo. Después de describir el contexto territorial, la metodología y las conclusiones del estudio, se hace un breve repaso de cuál es el estado del proceso en la actualidad.

Palabras clave: espacio catalán transfronterizo; Eurodistrito; gobernanza. 
Résumé. Livre Blanc sur l'Eurodistrict Catalan Transfrontalier: création du projet et restructuration territoriale

On présente le procès d'élaboration, la méthodologie, réflexions et conclusions du Livre Blanc de l'Eurodistrict Catalan Transfrontalier élaboré pour la Mission Opérationnelle Transfrontalière (MOT) et l'Université de Gérone (UdG). L'étude a pour but d'accompagner la définition et l'émergence d'un projet de territoire transfrontalier basé sur la réalité d'un domaine territorial partagé entre le département des Pyrénées Orientales et la province de Gérone. Le contenu du Livre Blanc se divise en trois accouchements: une diagnose transfrontalière complète, l'analyse des défis de ce territoire et les options de gouvernance du territoire transfrontalier. Après avoir décrit le contexte territorial, la méthodologie et les conclusions de l'étude, une brève révision est faite duquel l'état du procès est dans l'actualité.

Mots clé: espace catalan transfrontalier; Eurodistrict; gouvernance.

\title{
Abstract. The White Book of the Catalan Transborder Eurodistrict: project creation and territorial restructuring
}

We present the process of elaboration, methodology, reflections and conclusions of the White Book of Catalan Transborder Eurodistrict, elaborated by the Mission Opérationnelle Transfrontalière (MOT) and the University of Girona (UdG). The main purpose of this study is to help the definition and the emergency of a transborder territorial project based on the territorial reality shared between the department of the Oriental Pyrenees and the province of Girona. The content of White Book is divided into three parts: a complete transborder diagnosis, the analysis of the challenges of this territory and the options of governance of the transborder territory. After portraying the territorial context, the methodology and the conclusions of the study, a brief review of which the state of the process at the present time is made.

Key words: catalan transborder space; Eurodistrict; governance.

\author{
Sumari \\ Introducció Conclusió de l'estudi \\ Context territorial Estat del procés \\ Metodologia Bibliografia i fonts d'informació
}

\section{Introducció}

En aquest article, s'hi es presenta el procés d'elaboració, la metodologia, les reflexions i les conclusions del Llibre Blanc de l'Eurodistricte Català Transfronterer (MOT i UdG, 2008). Aquest treball, realitzat entre l'octubre de 2007 i el juliol de 2008, va ser un encàrrec de la Generalitat de Catalunya i el Consell General dels Pirineus Orientals a la Mission Opérationnelle Transfrontalière (MOT) i a la Càtedra de Geografia i Pensament Territorial de la Universitat de 
Girona $(\mathrm{UdG})^{1}$. L'origen d'aquesta missió es troba en la declaració d'intencions per a la creació de l'Eurodistricte de l'Espai Català Transfronterer firmada a Ceret l'any 2007 per part de vint-i-cinc institucions de Catalunya del nord i Catalunya del sud.

Les administracions consideren com a espai català transfronterer aquell constituït per una part dels territoris històricament catalans al voltant de la frontera estatal. D'una banda, les comarques de la Catalunya del nord, administrativament dins del departament francès dels Pirineus Orientals. De l'altra, les comarques de Catalunya del sud pertanyents a la província de Girona, a més de la part barcelonina de la comarca de la Cerdanya, limítrofa també amb la Catalunya del nord.

Un dels objectius de les administracions promotores del Llibre Blanc ha estat l'estructuració d'un eurodistricte de l'espai català transfronterer. Des del punt de vista jurídic, l'eurodistricte s'emmarca en la legalitat vigent, la del Tractat Franco-Espanyol de Baiona de 1995, de la legislació francesa sobre el «districte Europeu» (agost de 2004) i del reglament de la Unió Europea sobre l'«Agrupació Europea de Cooperació Territorial» (juliol de 2006) $)^{2}$.

L'estudi té per objectiu acompanyar la definició i l'emergència d'un projecte de territori transfronterer basat en la realitat d'un àmbit territorial compartit entre el departament dels Pirineus Orientals i les comarques de la província de Girona. Ha de servir també de base per a la creació d'un full de ruta perquè les diverses administracions elaborin els estatuts de l'Eurodistricte.

El contingut del Llibre Blanc es divideix en tres parts. La primera consisteix en un diagnòstic transfronterer complet del territori que engloba la província de Girona i el departament dels Pirineus Orientals. En concret, s'hi determinen els punts de convergència i les diferències entre un costat i l'altre de la frontera, el funcionament dels territoris, l'anàlisi dels fluxos socioeconòmics, la cooperació transfronterera existent i la visió recíproca dels actors de tots dos costats de la frontera.

La segona part consta d'una anàlisi dels reptes que es desprenen de les constatacions anteriors i que corresponen a temàtiques de cooperació, concretades en propostes de projectes transfronterers.

I, finalment, una última part està dedicada a la governança del projecte de territori transfronterer que implicaria l'execució del procés de l'Eurodistricte.

1. L'estudi va ser coordinat per la Mission Opérationnelle Transfrontalière amb seu a París i va ser realitzat de forma simultània en dos idiomes (francès i català). Per part de la MOT, va participar-hi Olivier Denert, director de projectes, Jean Rubió i Ludivine Salambo. La participació de la Universitat de Girona fou a càrrec de la Càtedra de Geografia i Pensament Territorial, concretament, dels membres que signen el present article.

2. De fet, existeixen projectes o organismes operatius semblants o pròxims a les altres fronteres de l'Estat francès, especialment l'Eurodistricte Pamina entre el nord de l'Alsàcia i el Palatinato-Mittlerer Oberrhein, però també, per exemple, la "plataforma transfronterera» de les Flandes francesa i belga. 


\section{Context territorial}

El territori de l'Eurodistricte acull 1.117.500 habitants, $10.247 \mathrm{~km}^{2}$ de superfície, 13 comarques històriques i 453 municipis.

Taula 1. Dades demogràfiques

\begin{tabular}{lcc}
\hline & Superfície $\left(\mathrm{km}^{2}\right)$ & Població 2006 (nre. habitants) \\
\hline Catalunya del nord & 4.116 & 427.000 \\
Catalunya del sud & 6.131 & 690.500 \\
\hline Espai Català Transfronterer & 10.247 & 1.117 .500 \\
\hline
\end{tabular}

Font: elaboració pròpia a partir del web de l'Idescat i de l'INSEE.

Aquest espai presenta una certa simetria en la seva configuració física, amb una planícia litoral i agrícola (el Rosselló i l'Empordà), una zona fronterera muntanyosa (Alberes, Vallespir, Conflent i Cerdanya) i una zona interior dividida en valls.

Com a unitat, es pot distingir entre un espai litoral dinàmic, delimitat pels tres pols urbans principals que són Perpinyà, Figueres i Girona, i una zona considerada més "deprimida", menys poblada i situada a la part més muntanyosa del territori transfronterer. La franja litoral concentra la majoria de les àrees urbanes de més de 10.000 habitants (Canet de Rosselló, Roses, Palafrugell, Palamós, Sant Feliu de Guíxols i Blanes-Lloret de Mar). Algunes d'aquestes ciutats formen part d'un sistema urbà consolidat (Canet dins de l'aglomeració de Perpinyà) o en curs de consolidació (Roses en el sistema urbà de Figueres).

L'estructura urbana, tanmateix, està molt més diversificada en el costat sud, cosa que no succeeix a la part francesa, on l'aglomeració de Perpinyà és l'únic centre de referència del departament. A la part sud, al contrari, la disposició urbana és policèntrica $i$ es troba en el marc d'un sistema urbà català també amb les mateixes característiques. Encara que, en els últims anys, Girona hagi adquirit un paper fonamental a la regió, el policentrisme ha estat i és encara un dels valors distintius i positius d'aquest territori que presenta un important nombre de centres urbans ben distribuïts, cadascun dels quals té una àrea comarcal d'influència i una estructura econòmica pròpia. Totes les comarques gironines disposen d'una ciutat o més que s'aproxima o supera els 10.000 habitants, un llindar que pot garantir una dotació de serveis i de funcions urbanes important (figura 1).

Aquesta diferència entre el nord i el sud de l'Eurodistricte no és anecdòtica, sinó fonamental per comprendre el funcionament de cada vessant de la Catalunya transfronterera, de les estratègies de desenvolupament i de les tendències observades en un costat i l'altre de la frontera (figura 2).

La part sud de l'espai transfronterer també es troba ben interconnectada, amb carreteres secundàries est-oest i corredors d'escala supraregional que enlla- 


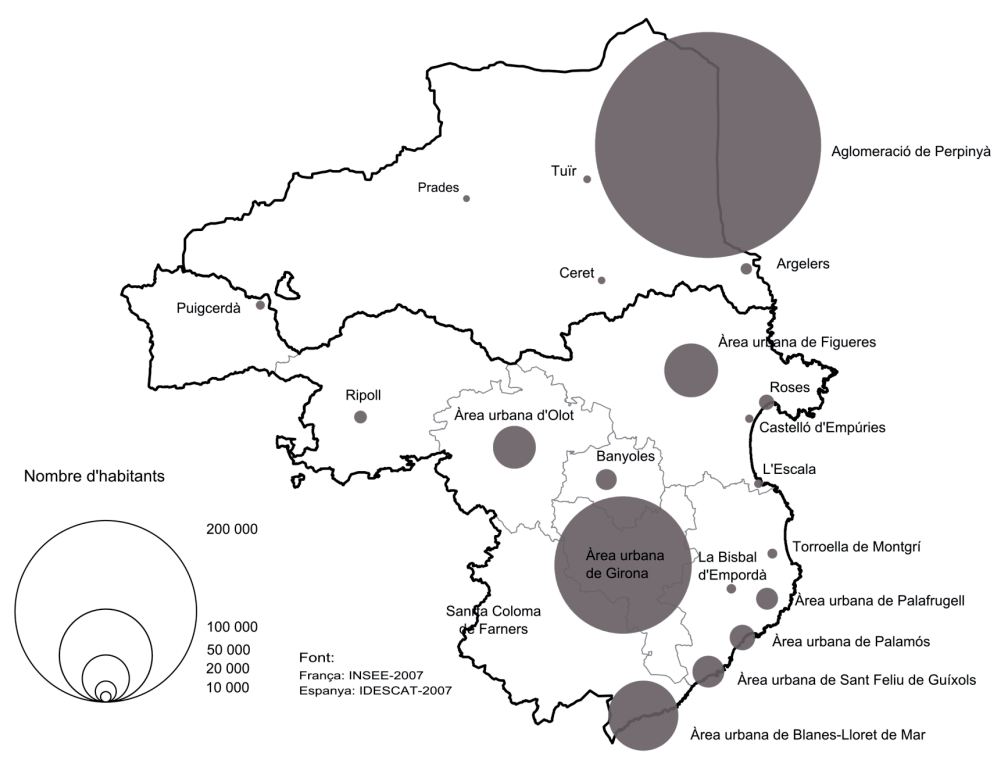

Figura 1. Xarxa urbana del Espai Català Transfronterer.

Font: Llibre Blanc de l'Eurodistricte (MOT i UdG, 2008: 14).

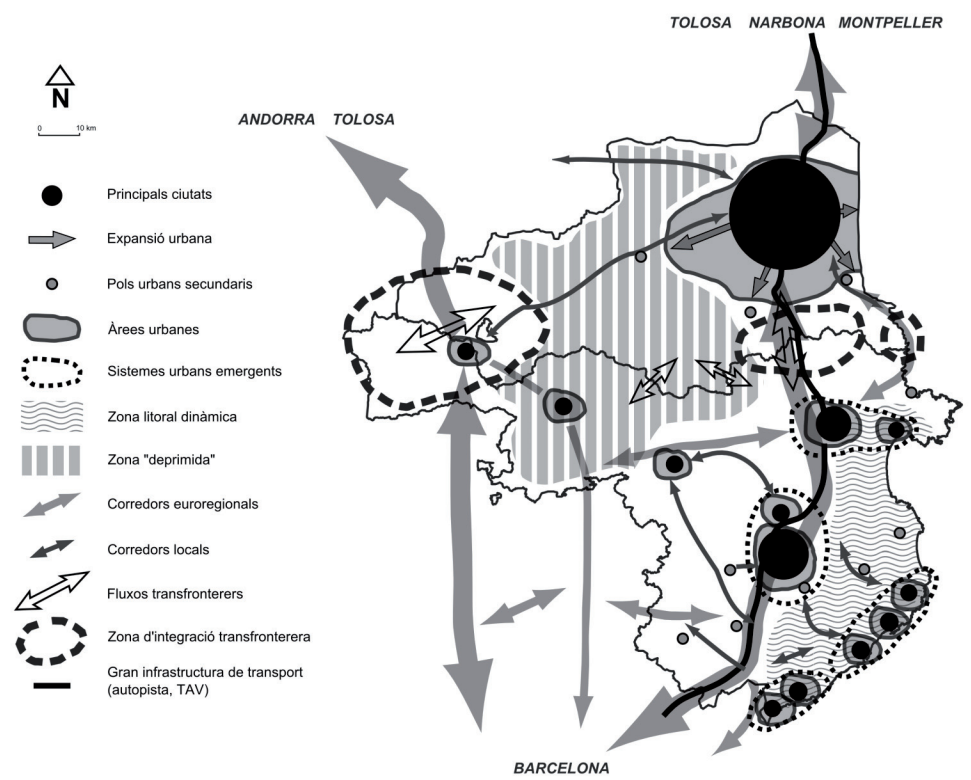

Figura 2. Esquema del funcionament territorial de l'Espai Català Transfronterer. Font: Llibre Blanc de l'Eurodistricte (MOT i UdG, 2008: 22). 
cen les ciutats principals amb Barcelona (Puigcerdà, per exemple, se situa a dues hores per carretera de la capital catalana via túnel del Cadí). Al contrari, en el costat nord, encara que Perpinyà i la part oriental del departament que cau en la seva òrbita estiguin ben connectades amb l'eix Barcelona-GironaMontpellier (traçat del futur TAV), tota la part cerdana es troba paradoxalment més propera a l'eix Tolosa-Barcelona que no pas a la capital del departament. Els principals eixos de comunicació de llarga distància en aquest territori nord són l'autopista A9 (la Jonquera-el Pertús) o la N22 a Andorra (eix TolosaAndorra-Barcelona). Les vies que compleixen una funció d'irrigació secundària són la carretera fins a Cervera (D914), les carreteres de la Cerdanya, els passos del Vallespir i la RD900 del Pertús.

Les zones transfrontereres més integrades dins de tot l'espai de l'Eurodistricte són, bàsicament, la Cerdanya, el pas del Pertús i l'accidentat litoral. Aquestes zones són les que mantenen fluxos transfronterers de proximitat més importants, ja sigui per raons professionals, de compres, lleure, etc. $\mathrm{Al}$ contrari, la zona més «deprimida» és la menys integrada a nivell transfronterer, a causa, sobretot, de la dificultat d'accedir-hi per carretera i la presència d'un relleu que constitueix un obstacle natural per a les comunicacions entre tots dos costats de la frontera.

El territori transfronterer està ordenat per un cert nombre de documents de planificació territorial i urbanística. En el costat francès, hi ha esquemes de coherència territorial (SCOT) i plans locals d'urbanisme (AGRADAT), com també territoris de projecte que de vegades se superposen a les àrees de planificació, però amb perímetres diferents (els denominats pays i un parc natural regional). En el costat sud català, hi trobem plans directors territorials, plans territorials parcials, plans directors urbanístics i plans urbanístics municipals.

La juxtaposició de diferents perímetres d'estructures administratives, de documents de planificació i, finalment, de projectes de territori poden crear una certa confusió i una gran complexitat en la conducció de les polítiques d'ordenació del territori i de desenvolupament local.

\section{Metodologia}

A partir d'aquest context territorial descrit a grans línies, la realització inicial d'una anàlisi i un diagnòstic del territori català transfronterer havia d'aportar un marc de referència fiable en el procés de concreció i gestió posterior de l'Eurodistricte. Una fase prèvia d'aquesta primera part del treball va ser l'examen dels documents existents sobre l'àmbit d'estudi, per evitar duplicacions i aprofitar al màxim el material editat. Una constatació va ser l'existència de nombrosos estudis d'anàlisi en tots dos costats de la frontera catalana, però amb l'escala transfronterera pràcticament absent, la qual cosa testimonia el recorregut que encara resta en aquest sentit. En l'anàlisi estadística dels dos àmbits territorials, s'hi van constatar també grans diferències en l'actualització de les dades. A la part francesa, al trobar-se en un període intercensal, la majoria de la informació es refereix a 1999, i aquesta ha quedat 


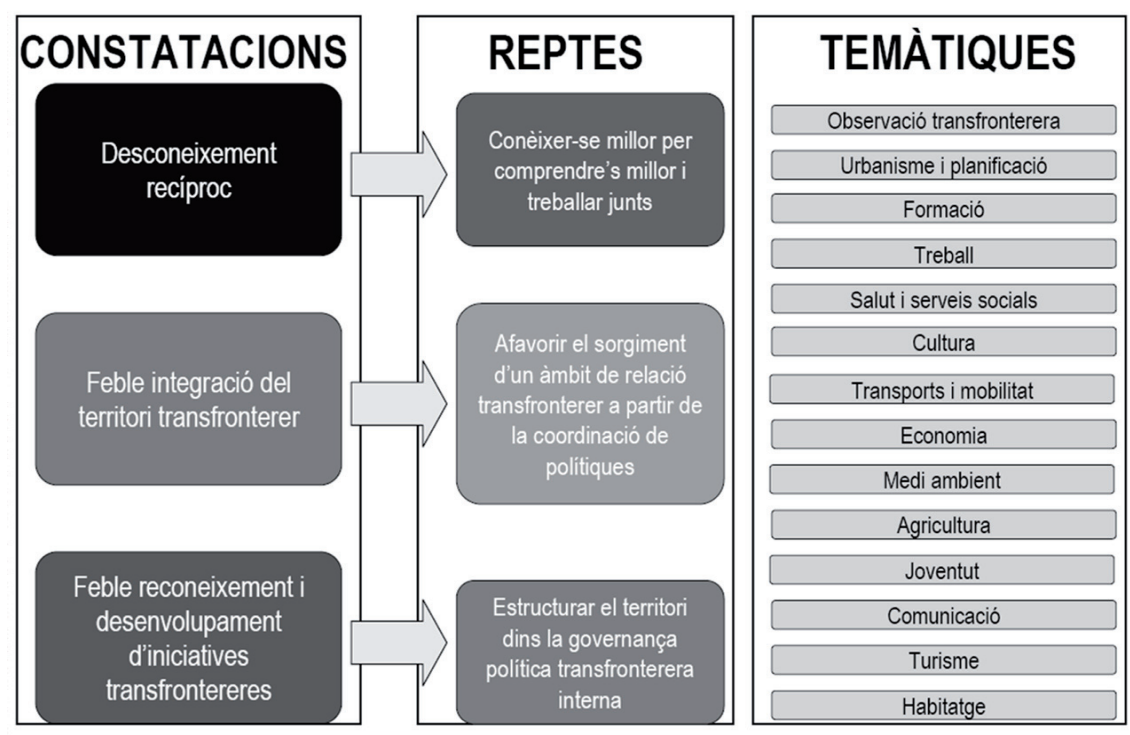

Figura 3. Resultats en les constatacions, els reptes i les temàtiques. Font: Llibre Blanc de l'Eurodistricte (MOT i UdG, 2008: 82).

pràcticament obsoleta. En canvi, a la part espanyola, hi ha dades molt més actualitzades, ja sigui pel cens (2001) o, sobretot, per la tasca de recopilació de l'Institut d'Estadística de Catalunya (Idescat) de nombrosos sectors i àmbits administratius.

Un element metodològic important de l'estudi va ser l'ampli treball de camp realitzat, que va permetre establir una primera identificació de les temàtiques més importants, dels projectes ja existents i dels actors clau del territori. Aquesta acció va facilitar aprehendre el territori físicament i visualment, amb tots els seus components, especialment les zones frontereres de pas. Es van entrevistar més de cinquanta persones ${ }^{3}$ de tots dos costats de la frontera. Es van consultar les administracions locals de tots els nivells i en tot el conjunt del territori, però també els actors socioeconòmics que tenen un paper transfronterer fonamental en aquest espai. A més, es va tenir en consideració tant l'àmbit urbà com el rural. Les entrevistes van permetre igualment informar els actors sobre el procés de creació del propi Eurodistricte.

A la segona part, i a partir de la diagnosi realitzada i del contacte amb els actors del territori, es va aplicar un esquema propositiu ordenat jeràrquicament per determinar projectes d'actuació (figura 3). Després d'identificar una sèrie de constatacions bàsiques, es van proposar uns reptes o desafiaments que l'Eurodistricte havia de superar a través d'accions de futur. L'esquema es ramifica fins a la identificació de 13 temàtiques i 18 projectes, tot seguint la pauta següent:

3. Se'n pot consultar la llista a l'annex del Llibre Blanc. 
Les temàtiques i els projectes proposats van ser escollits segons criteris de diversitat temàtica, d'escala (que afecten una part de l'àmbit o tot), dels llocs afectats (rurals, urbans i periurbans, litoral, muntanya) i dels actors implicats. Es pot dir que n'hi ha alguns que responen a línies de relació ja iniciades entre una part i una altra de la frontera a través de projectes del programa europeu Interreg entre França i Espanya ${ }^{4}$, i que, per tant, interessa consolidar-los i donar-los un nou impuls i un marc més estable.

Els projectes establerts en el Llibre Blanc van des de la creació d'un observatori del territori transfronterer, fins a la implantació d'una institució de formació i investigació sanitària i social, o a facilitar la creació i recuperació d'empreses en aquest espai. Alguns, com ara la reflexió sobre la creació de línies de transport públic, per l'interès que tenen i la necessitat que n'hi ha, van comportar ja l'impuls d'estudis paral.lels en el mateix moment en què es realitzava el Llibre Blanc de l'Eurodistricte.

Cada projecte es descriu àmpliament en una fitxa on es detalla l'acció i els resultats esperats, el territori implicat, els socis que hi poden participar, el context en relació amb els avantatges o els inconvenients que poden existir, la font de finançament possible i el calendari previsible.

Finalment, una tercera fase de l'estudi va tenir per objectiu obtenir una visió global de les inquietuds dels representants polítics socis d'aquest espai transfronterer sobre la possible governabilitat $i$, en concret, de com es podia organitzar el futur organisme de l'Eurodistricte, tant a nivell polític, com tècnic i jurídic. Per poder recollir les diferents posicions dels actors, es va elaborar un qüestionari per als representants de les institucions associades de l'Espai Català Transfronterer, és a dir, vint-i-tres destinataris. La resposta va ser del $90 \%$, la qual cosa indica l'interès real en el projecte de l'Eurodistricte. Els resultats d'aquesta darrera fase constitueixen, doncs, una sòlida base de reflexió per a l'estructuració jurídica posterior de la governança de l'Eurodistricte de l'Espai Català Transfronterer.

\section{Conclusions de l'estudi}

Finalment, descrivim de forma sintètica les conclusions del Llibre Blanc, estructurades en quatre arguments que mostren, especialment, quina és la posició dels actors implicats en l'espai transfronterer i quins poden ser els avantatges de la creació d'un eurodistricte de l'Espai Català Transfronterer.

\section{Interaccions limitades que s'han de reforçar}

A diferència d'altres territoris situats a una banda i l'altra de la frontera francesa, l'Espai Català Transfronterer es caracteritza per tenir una frontera molt menys

4. En el marc del programa Interreg IIIA França-Espanya (2000-2006), es van realitzar 51 projectes dins del territori de l'Espai Català Transfronterer, amb un cost total de 46.357.050 euros. Del pressupost total del programa Interreg IIIA França-Espanya, la part dedicada a l'espai de l'Eurodistricte català va representar el $26 \%$ en aquesta edició. 
permeable per a les poblacions properes que hi viuen. Malgrat les característiques geogràfiques sovint semblants, les pràctiques i el tipus de desenvolupament han fet evolucionar els dos vessants de forma diferent en el transcurs dels darrers decennis, on la frontera constitueix encara un vertader obstacle polític o cultural. En aquest sentit, els fluxos de treballadors fronterers, poc nombrosos, es concentren essencialment a la Cerdanya, mentre que els fluxos relacionats $\mathrm{amb}$ les pràctiques comercials se situen majoritàriament al coll del Pertús. La interrelació funcional residencial continua essent relativament dèbil, la qual cosa explica també la relativa feblesa dels fluxos transfronterers de proximitat.

Malgrat la presència de la cultura catalana en un cantó i l'altre de la frontera, la llengua és considerada una barrera, tant pels actors del nord com del sud. Si bé molts francesos dels Pirineus Orientals entenen el català sense parlar-lo necessàriament, els catalans del sud no es troben sempre en condicions de comprendre el francès. Tanmateix, l'aprenentatge del català coneix una certa recuperació al costat nord i podria tornar a esdevenir la llengua d'intercanvi i de treball en el territori transfronterer, sense minimitzar, però, la importància del francès o del castellà.

\section{Legitimitat de l'Eurodistricte al servei de la població}

En el transcurs d'aquest estudi, han estat entrevistats nombrosos actors (municipis, agrupació de municipis, comarques, cambres de comerç, universitats, organismes públics, etc.), la majoria dels quals coincideix a reconèixer la legitimitat del procés de l'Eurodistricte. L'escala del procés sembla pertinent i l'Eurodistricte ha d'exercir el paper d'unió i d'estimulador de totes les iniciatives transfrontereres en curs i futures, entitat que fins ara mancava en aquest territori. En efecte, fins avui, els projectes transfronterers promoguts pels diferents actors del nord i del sud no s'han basat en cap estratègia transfronterera global prèvia. L'Eurodistricte ha de respondre a aquesta mancança i assumir un paper clau en matèria de cooperació transfronterera.

En tots els casos, els actors interrogats desitgen que l'Eurodistricte no sigui una estructura suplementària sobre un territori que disposa ja d'un cert nombre de nivells administratius, sobretot al costat francès. Es tracta d'acompanyar les diferents iniciatives transfrontereres existents i permetre que siguin integrades dins una dinàmica territorial més àmplia. També és important per a l'Eurodistricte promoure o dirigir projectes molt concrets, entenedors per a la majoria de la població, que podrà, així, identificar-se millor amb el territori transfronterer on viu.

Una vintena de projectes identificats en el marc d'aquest estudi poden constituir un sòcol d'accions concretes que caldria establir i respondre als diferents reptes identificats: millorar el coneixement recíproc dels actors per tal que es puguin comprendre millor i treballar junts; afavorir l'emergència d'un àmbit de vida transfronterer a través de la coordinació de les polítiques, i estructurar el territori en la governança política interna. Aquests projectes tenen en compte la diversitat temàtica de l'Espai Català Transfronterer, ja sigui en l'àmbit de l'economia, del treball, de l'agricultura, del medi ambient, dels transports públics, del turisme, de la cultura, de la salut, etc. 


\section{Voluntat comuna de governança}

Els actors interrogats desitgen que l'Eurodistricte de l'Espai Català Transfronterer es doti d'un organisme de governança que doni al territori una visibilitat política forta i la capacitat operacional de reforçar la cooperació transfronterera per a un desenvolupament concertat.

Els objectius principals d'aquest organisme de governança han de ser: la definició d'una estratègia transfronterera que apunti a fer de l'Eurodistricte un pol de desenvolupament, l'impuls de les accions transfrontereres estructurants per a l'Eurodistricte, la creació d'una plataforma d'intercanvis i d'un lloc de concertació per als socis de l'Eurodistricte i, finalment, l'acompanyament dels promotors de projectes transfronterers membres de l'Eurodistricte.

Aquest organisme ha de representar els diferents components del territori transfronterer (urbà, rural, litoral, muntanya, etc.) i la majoria dels organismes públics o de les institucions de nivell superior, en funció de l'adequació de les seves competències amb les diferents accions que caldrà establir. No obstant això, com en nombrosos altres eurodistrictes, no es considera que els estats francès i espanyol hagin de ser plenament membres de l'organisme de governança (organisme integrat per col-lectivitats territorials). Els estats són, tanmateix, susceptibles d'ésser associats a certes accions o de tenir un paper d'observador i/o de facilitador.

La creació d'aquest organisme implica una reflexió sobre les modalitats d'associació dels actors pertinents, sobre la definició dels criteris d'adhesió, així com sobre la representativitat política dels membres adherits dins de l'estructura i la contribució financera perquè puguin funcionar.

\section{Una estructura juridica operativa}

L'actual procés d'estructuració de l'Eurodistricte hauria de portar, segons el vot de la majoria dels actors interrogats, a la creació d'una estructura jurídica transfronterera.

L'interès de dotar l'organisme d'una personalitat jurídica estaria a poder actuar com un operador únic, disposar d'una autonomia financera (pressupost propi) i oferir garanties financeres per a la gestió de fons públics (fons estructurals europeus, sobretot), fer contractes, respondre a ofertes de projectes i tenir personal propi. Aquest organisme realitzaria tasques de manera única al servei dels seus membres adherits. Tindria igualment la capacitat de portar ell mateix projectes (promotor).

Finalment, la majoria dels actors interrogats desitgen que l'organisme de governança de l'Eurodistricte de l'Espai Català Transfronterer pugui prendre la forma d'una agrupació europea de cooperació territorial (AECT), més que la d'un consorci. Aquesta opció s'explica per la facultat de l'AECT de donar més visibilitat política a l'Eurodistricte a nivell europeu, reunir una col-laboració transfronterera més àmplia que el consorci i, finalment, poder triar el país per establir-hi la seu. 


\section{Estat del procés}

El novembre de 2008, es va presentar el Llibre Blanc de l'Eurodistricte i es va aprovar el full de ruta cap a l'Eurodistricte de l'Espai Català Transfronterer en presència de tots els socis que integren el projecte. En definitiva, com s'ha explicat, es tracta de dissenyar una estratègia de desenvolupament compartida, establir polítiques transfrontereres de caràcter vertebrador, crear un lloc de concertació i una plataforma d'intercanvis per als diferents actors, assessorar i acompanyar els impulsors dels projectes i donar més visibilitat i projecció exterior al conjunt d'aquest espai.

El novembre de 2009, data en la qual es complien 350 anys de la frontera actual, les institucions que formen part del projecte van acordar els estatuts per convertir l'Eurodistricte en una agrupació europea de cooperació territorial. Un cop pres l'acord, els estatuts es van trametre als estats francès i espanyol, que són les instàncies que hi han de donar el vistiplau definitiu. Al setembre de 2010, només s'hi han rebut les objeccions per part de l'Estat espanyol, mentre que el francès encara no s'ha pronunciat.

\section{Bibliografia}

BECAT, Joan (2007). «Catalunya i els models espanyol i francès d'organització territorial. Uns apunts i una reflexió crítica». A: TORT, Joan; PAÜL, Valerià i MaluQUer, Joan (eds.). L'organització del territori, un repte per al segle XXI. Barcelona: Galerada - Fundació Universitat Catalana d'Estiu.

Beltran, Susana (2010). «Els organismes de cooperació territorial a Europa: una mirada cap al futur». Documents d'Anàlisi Geogràfica, 56/1, 57-69.

Castex, Jean-François (2005). La Catalogne Nord en quête d'identité. Perpinyà: TDO.

Generalitat de Catalunya (2006). Pla director territorial de l'Empordà. Barcelona: Departament de Política Territorial i Obres Públiques de la Generalitat de Catalunya, setembre.

HaRguindÉGUY, Jean-Baptiste (2007). La frontière en Europe: un territoire? Coopération transfrontalière francoespagnole. París: l'Harmattan.

Holz Jean-Marc i Giband, David (2006). «Le TGV Perpignan / Barcelone: quels effets de mobilité?». A: Feliu, J. (coord.). Étude cadre des effets du train à grande vitesse sur la ville moyenne. Figueres: Ajuntament de Figueres.

JoRDI, Moisès (2008). Els conflictes territorials transfronterers entre les Comarques Gironines i la Catalunya Nord: Estudi de base de l'Eurodistricte de l'espai transfronterer català, febrer.

Maury, Caroline (2007). «Construire le "Pays Catalan”: Les dynamiques d'un échange politique territorialisé». Congrès AFSP. Toulouse.

Mission Opérationnelle Transfrontalière (2007). Enjeux fonciers et immobiliers sur les littoraux basque et catalan, Partie 2: Le littoral transfrontalier catalan. Ministère de l'Ecologie, du Développement et de l'Aménagement Durables, octobre.

MOT (Mission Opérationnelle Transfrontalière) i UdG (Universitat de Girona) (2008). Livre Blanc de l'Eurodistrict, pour un avenir transfrontalier / Llibre Blanc de l'Eurodistricte, per a un futur transfronterer. París: Generalitat de Catalunya i Consel General Pyrénées Orientales. 
Oliveras, Xavier; Durà, Antoni i Perkmann, Markus (2010). «Las regiones transfronterizas: balance de la regionalización de la cooperación transfronteriza en Europa (1958-2007)». Documents d'Anàlisi Geogràfica, 56/1, 21-40.

Pays Pyrénées-Méditerranée (1999). Diagnostic et analyse stratégique. Perpinyà, juliol.

PNR Pyrénées-Catalanes (2004). Charte, Diagnostic socio-économique, març.

Vicente, Joan (2003). «La Regió de Girona: un model territorial en transformació, amb potencial i fràgil». Papers, 39 (monogràfic «Estratègies territorials a les regions catalanes», Institut d'Estudis Regionals i Metropolitans de Barcelona, 61-72.

\section{Adreces web}

INSEE : www.insee.fr [data de consulta: 15 de setembre de 2010]

IDESCAT: www.idescat.cat [data de consulta: 15 de setembre de 2010]

Programa Interreg IIIA España-Francia: www.interreg3france-espagne.org [data de consulta: 17 de setembre de 2010] 